\title{
A CANÇÃO: UM CANAL DE EXPRESSÃO DE CONTEÚDOS SIMBÓLICOS E ARQUETÍPICOS
}

\author{
The Song: a Way to Express Symbolic and Arquetype Issues
}

Sofia Cristina Dreher ${ }^{1}$

\section{Resumo}

Este trabalho visa fazer uma reflexão sobre a utilização da canção no processo musicoterapêutico. Propõese uma análise maior dos conteúdos que são expressos pela canção. Para tanto, fez-se uma pesquisa sobre o pensamento simbólico. Esses questionamentos surgiram a partir de um trabalho com pacientes oncológicos. Palavras-chave: Canção; Canal de Expressão; Prática Musicoterapêutica.

\section{Abstract}

This text aims a reflection about the utilization of the song in a musictherapeutic proceeding. It recommends a greater analysis of the contents expressed through the song. Therefore a research about the symbolic thinking was effectuated. These questions appeared during a work with cancer patients.

Keywords: Song; Expression Channel; Musictherapeutic Practice.

1 Musicoterapeuta (Faculdade de Artes do Paraná). Aluna da especialização em Comunicação e Semiótica: teoria e crítica da sociedade de informação, da Pontifícia Universidade Católica do Paraná.

Endereço para contato: Rua Ubaldino do Amaral, 360 ap. 17 CEP 80060-190 - Curitiba-PR

E-mail: sofiasoft@yahoo.com.br 
A canção, enquanto linguagem, é considerada um canal de expressão, que contém conteúdos que se relacionam com a história do indivíduo. A canção, como canal de expressão, abre as portas do inconsciente do indivíduo, a partir de uma abordagem simbólica.

\section{0 pensamento simbólico}

O pensamento simbólico se constitui de três entidades que estão interligadas, os complexos, os arquétipos e os símbolos.

Segundo o dicionário Aurélio, complexo é o grupo ou conjunto de coisas, fatos ou circunstâncias que têm qualquer ligação ou nexo entre si. Partindo para um conceito mais direcionado à área de psicologia, tem-se algo mais completo quando Ulson (1998) coloca que complexo é um "agrupamento de idéias, sentimentos e imagens com um núcleo em comum e que se comporta como uma individualidade." (p.23).

Os dois conceitos acima mencionam conjunto e agrupamento de idéias que se relacionam, mas há um aspecto importante a ser ressaltado, 0 de que eles unem sob uma carga de sentimento, emoção muito forte. Assim, podem-se relacionar os complexos com os temas de vida que se tem. Kast (1997) fala dos complexos como pontos suscetíveis de crise no indivíduo, ou seja, são temas com os quais se lida no transcorrer da vida, temas que movem essas vidas. É importante ressaltar que todos têm complexos e que eles é que dão a dinâmica à vida, é em função deles que se procura a transformação, o equilíbrio na psique, na vida.

Para falar a respeito dos complexos, precisa-se antes localizá-los na estrutura da psique. Eles "residem" no inconsciente, ou seja, num local onde não se tem acesso, a não ser por meio dos sonhos. Quando se quer e consegue tornar esses conteúdos conscientes, ocorre então o que Jung chamou de dialética entre consciente e inconsciente, ou seja, passa a existir um "intercâmbio" de informações. Mas enquanto alguns conteúdos complexos não se tornam conscientes, eles agem sobre as pessoas inconscientemente, portanto sem controle e percepção dessa ação. Esse é o aspecto negativo do complexo, o da dominação. Perante esse complexo, essa problemática, passa-se a reagir sempre dentro de um padrão de comportamento e de idéias.
Nem sempre se tem estrutura e suporte para receber devidas informações do inconsciente. Os complexos que se formaram a partir de determinadas situações, às quais se foi confrontado durante a vida, é que nos deixaram suas marcas positivas ou negativas, prazerosas ou não. A repressão desses conteúdos transforma-os em complexos inconscientes. Lidar com o inconsciente se torna muitas vezes algo dolorido, pois retoma os temas que se fez questão de esquecer. A hora e o momento de lidar com esses conteúdos não podem ser impostos, pois, caso contrário, o bloqueio e a repressão serão ainda maiores. "O caminho do processo de lidar com os complexos não pode ser nem o da defesa nem o do controle; trata-se de permitir que os complexos se desdobrem em fantasias, de vê-los e compreendê-los em padrões e então incorporá-los ao consciente por meio do trabalho com o símbolo." (Kast, 1997, p. 47)

A partir do momento em que existe determinado comportamento frente a um tema, passa-se à compreensão dessa ação e acaba-se por incorporá-la ao seu consciente, ou seja, pode-se prever que aquele tema mobiliza a pessoa e, dessa forma, até torna o complexo mais sutil, menos prejudicial a si e aos que o rodeiam. Ao final, retorna-se ao ponto de partida do pensamento de Jung, o de que o indivíduo deve buscar o equilíbrio, a dialética, nem a defesa nem o controle, mas a compreensão e adaptação. "Contudo, apesar desses aspectos puramente pessoais, que dependem das experiências vividas por esses indivíduos, há algo que dá forma a tais experiências, que molda esses conglomerados de idéias e emoções segundo padrões típicos da nossa espécie humana. O complexo, dessa forma, um núcleo inatingível abstrato, puramente formal, que Jung chamou de arquétipo." (Ulson, 1998, 33)

Arquétipos são, portanto, segundo Ulson (1998), as formas de agir e pensar, que temos em comum com todos os seres humanos. São as estruturas básicas da psique e são herdadas. Para que uma idéia, um comportamento seja arquetípico, ele deve ter aparecido em diversas épocas, regiões e civilizações. Por esse motivo é que se fala que os mitos são o veículo mais "exato" dos arquétipos, porque falam de acontecimentos passados que tocam, ou seja, que espelham os comportamentos atuais. "O arquétipo é visto como um conceito puramente formal, um arcabouço então preenchido com imagens, idéias, temas, etc. A for- 
ma ou padrão arquetípico é herdada, mas o conteúdo é variável, sujeito a mudanças históricas e ambientais."(Samuels, 1989, p. 43)

Portanto, arquétipos são os padrões que são passados, são herdados, transmitidos, como os mitos, mas cujo conteúdo advém da época, do ambiente. E é essa possibilidade de lidar, relacionar o passado com o presente que dá a dimensão de um tempo atemporal ao que se chama de tempo mítico.

No pensamento mítico, o tempo não é quantitativo, contínuo, homogêneo e infinito, como o conhecemos através da ciência. Tampouco é como o tempo que Mircea Eliade chama profano - esse com que convivemos -, contado em horas, dias, meses, anos, séculos, milênios, compartimentado por relógios, agendas, calendários ou História. Não é conceito abstrato, é vivência - conhecido através da emoção, vivido como sagrado. (Seabra, 1996, p.89)

A partir do momento em que o indivíduo tem consciência de que a dor não é só sua, mas também de outras pessoas, ele se coloca num plano maior, o da humanidade. É por meio desse lugar, posicionamento que ele dá um sentido maior à vida, que ele se introduz num plano transcendental, onde passa a entender que outras pessoas vieram antes dele e que virão outras depois, e, o mais importante, de que há um sentido após a morte. "... o indivíduo que sofre pode relacionar seus problemas aos problemas que sempre constituíram o ser humano; desperta-se sobretudo a esperança de poder viver com os problemas, de dominar a vida." (Kast, 1997, p.113)

Quando se diz que os arquétipos são os padrões, são os "olhos do observador" e não aquilo que ele observa, precisa-se incluir um conceito que surgiu juntamente com o arquétipo, o do inconsciente coletivo. Quando se fala dos complexos, localizam-se os dentro do inconsciente, agora especificado como inconsciente pessoal, por se tratar de conteúdos provindos de experiências pessoais, mas, para inserir esses conteúdos numa abrangência maior, o da humanidade, precisa-se conferir aos conteúdos arquetípicos a localização no inconsciente coletivo, do qual todos fazem parte.

Como já foi esclarecido anteriormente, 0 arquétipo é algo formal, são os olhos do observador, mas aquilo que ele observa, o conteúdo, surge pelas imagens arquetípicas, o símbolo.
A própria definição de símbolo dada por Jung pode ser resumida como referindo-se à melhor formulação possível de um conteúdo psíquico relativamente desconhecido que não pode ser compreendido pela consciência. Para Jung, um símbolo não é um sinal; este se refere àquilo que já é conhecido (um sinal de estrada, um sinal indicando o banheiro, etc). A psique produz espontaneamente símbolos quando o intelecto está confuso e não sabe como lidar com uma situação interna ou externa. Um símbolo não é analogia que simplesmente elucida ou traduz." (Samuels, 1989, p.118)

Partindo da citação acima, tem-se a função do símbolo, a de mediar o inconsciente com 0 consciente. Como foi visto anteriormente, os complexos, bem como os conteúdos arquetípicos, rompem a mente consciente, num intuito de equilibrar os pensamentos e comportamentos, e isso só é possível por meio do símbolo, que é o veículo de comunicação entre o inconsciente e o consciente. É importante ressaltar que é por meio do símbolo que se tem a possibilidade de uma melhor compreensão e adaptação de conteúdos do inconsciente, pois, do contrário, acabariam reprimindo-os e negando-os.

Quando se lida com o símbolo, faz-se necessária a distinção do sinal. Como citado acima, o sinal é algo conhecido de todos e cujo significado é igual para todos. Já o símbolo trata de elementos do cotidiano dotados de significados, dentro de um contexto de história e de vida do indivíduo, cujo significado não pode ser traduzido, decifrado, mas sim ampliado, ressignificado. "A etimologia do conceito mostra o símbolo como algo composto. Apenas quando combinado é um símbolo, tornando-se símbolo de alguma coisa." (Kast, 1997, p.19)

Aqui se retoma a importância de se contextualizar o símbolo, ao qual se é defrontado. Se não se tiver o cuidado de localizar o símbolo dentro do contexto de vida do indivíduo, cai-se na tradução do símbolo, o que acarretaria em interpretações "certas" ou "erradas". Um símbolo jamais terá apenas um significado, mas muitos, pois cada vez que se entra em contato com ele, ele diz algo do qual se está precisando saber. "Mostra a verdade e a realidade interiores do paciente como realmente são, não como eu conjecturo que sejam e não como ele gostaria que fossem, mas como 
elas são." (Whitmont, 1969, p.34) É por esse motivo que, quando um símbolo "atinge" o indivíduo, ele causa mudanças, transformações, porque ele é real, o indivíduo não pode fingir, ignorar a sua existência, para tanto, tem que estar preparado. "Para vivenciar os símbolos realmente como tais e em última análise o que importa é a vivência - e não apenas vê-los como sinais, devemos estar prontos para nos deixar tocar emocionalmente por eles." (Kast, 1997, p.25)

\section{0 pensamento simbólico na canção}

Suzanne Langer amplia o olhar perante as obras de arte. Faz buscar o sentimento dentro delas. Em suas palavras: "A arte é a criação de formas simbólicas do sentimento humano." (Langer, 1953, p.42), traduz-se bem o valor que as obras de arte contêm e carregam. Não se trata apenas do sentimento que o artista imprime na obra, mas também do sentimento com que se aprecia essa obra e, na linguagem musical, com que se expressa ela.

Portanto, "a música é 'forma significante', e sua significação é a de um símbolo, um objeto sensorialmente articulado que, em virtude de sua estrutura dinâmica, pode expressar as formas da experiência vital que a linguagem é especialmente inadequada para transmitir. Sentimento, vida, movimento e emoção constituem seu importe." (Langer, 1953, p.34)

Aqui se tem a oportunidade de compreender melhor o envolvimento de cada indivíduo com a música, com a canção, o que "atrai" em determinadas canções e como elas falam, ao mesmo tempo, da vida, de momentos que se está vivendo. Para isso serão tomados três termos, o significante, o significado e o signo, os quais aparecem também dentro do mito.

Como diz a citação acima, a música é o significante, ou seja, é uma forma, uma obra, um veículo, um canal. O conteúdo dessa forma, e como relatado acima, formas de experiência vital, como sentimento, emoção, vida, é denominada como significado. A autora ainda ressalta um aspecto de grande valia, a estrutura dinâmica que a música tem e que possibilita imprimir na obra as experiências humanas, quase que de forma real, tamanha é a comoção que causa. Isso fica muito claro quando se entende que a música possui um tempo, um andamento, um fluir, um prosseguir, um retornar, um fim, ou seja, todos esses aspectos também fazem parte das vidas. Mas cabe ressaltar aqui que apenas esses dois termos, o do significante e o do significado, não teriam a menor valia se não fosse a existência de um terceiro, que depende muito de cada indivíduo, ou seja, o símbolo. Esse sim tem o papel de associar e de dar a significação da obra de arte com a obra da vida, ou seja, as vidas. Pois, para que se possa associar a forma (significante) com o conteúdo (significado) e proporcionar uma significação, precisa-se passar a obra e a impressão pelos sentimentos para que ela expresse algo para o indivíduo. É mais ou menos como se tivesse que passar tal obra e conteúdo pelo "filtro de nossas experiências de vida". Feito isso, não é por acaso que muitas, senão todas, das canções que se canta, escuta, aprecia, traduzem o momento pelo qual se está vivendo.

A canção carrega conteúdos de experiências humanas, vitais, pelas quais também se passa, vive, e daqui provêm as associações, significações que ligam as pessoas diretamente, numa conexão atemporal.

Os afetos existem no tempo, como a música, e o tempo passa, não há como pegá-lo, estancá-lo. Há sim. As canções seriam uma das formas privilegiadas de fazer isso. Elas guardam blocos de tempo, de memória. E com seu formato circular, de eterno retorno, voltam sempre resgatando a carga afetiva com que as associávamos - sem o perceber, e daí vem o seu poder - na época em que as ouvíamos ou cantávamos." (Costa, 2001, p. ix)

Já foi relatado anteriormente 0 valor da canção quanto à associação, significação que se tem com ela devido aos conteúdos de obras distintas, a saber, arte e vida, porém de experiências vitais e humanas iguais. $\mathrm{O}$ autor acima traz um outro aspecto muito importante e de grande poder para a Musicoterapia, o de eterno retorno, ou seja, quando se canta hoje uma canção que se aprendeu na infância, aquele tempo retorna ao tempo do hoje. Mais importante do que o retorno do tempo, são as cargas afetivas que, em alguns casos, podem conter complexos não resolvidos que retornam, estando anteriormente "escondidos" no inconsciente, e agora emergem no consciente. Aqui novamente se confirma a tese de que a canção é um canal de expressão. A canção, como relatado 
acima, tem o poder de fazer emergir os complexos, as experiências vitais, que nem sempre são tão claras enquanto apenas vividas. À medida que se canta, os conteúdos das canções vão sendo associados com os conteúdos dos indivíduos e, através dessa significação, é que se toma conhecimento de pontos anteriormente encobertos, que impossibilitavam um entendimento, um equilíbrio maior do ser e de suas experiências vitais. "Há momentos de entraves, bloqueios, onde não conseguimos traduzir em palavras o que sentimos. As canções podem permitir, então o emergir dos conteúdos bloqueados." (Millecco Filho, 2001, p. 98)

"Quando as palavras entram para a música, elas não são mais poesia ou prosa, são elementos da música. Sua tarefa é ajudar a criar e desenvolver a ilusão primária da música, o tempo virtual, e não a da literatura, que é outra coisa; assim, elas desistem de seu status literário e assumem funções puramente musicais." (Langer, 1953, p.156)

Muitas pessoas acreditam que não é função do Musicoterapeuta dar importância às letras das canções, mas apenas à estrutura musical desta. Talvez porque entendam que a poesia é apenas uma comunicação verbal e esquecem que na canção ela não está sozinha e nem pode "sobreviver" individualmente. Não é possível imaginar, lembrar e até recitar a canção Desafinado, de Tom Jobim, sem a estrutura musical. Consegue-se entender 0 termo desafinado, a passagem "...que isso é bossa nova, isso é muito natural"? "Quando palavra e música se conjugam na canção, a música engole as palavras; não só meras palavras e sentenças literais, mas até mesmo estruturas literárias de palavras e poesia. A canção não é um compromisso entre poesia e música, embora o texto tomado em si mesmo seja um grande poema; a canção é música." (Langer, 1953, p.158)

A autora acima expõe a unicidade da canção, nela não existe música sem poesia, nem poesia sem música. Assim como se pediu anteriormente para recitar a canção Desafinado sem a música, o contrário também se faz necessário. Toda vez que a melodia surge nos ouvidos, automaticamente a letra, a poesia também vem, pois ambas são uma unidade, uma complementa o sentido da outra.

A partir desses entendimentos, reafirmase novamente que a canção é um canal de expressão e que é tarefa sim, do Musicoterapeuta, dar suporte para os conteúdos pessoais que vêm atrelados a essa expressão, esta comunicação.
Quando se produz, se expressa um som, uma canção, esse som se reverbera, se expande, amplia o símbolo da arte. Essa, carregada de experiências vitais, amplia as experiências dos indivíduos, não apenas no tempo do hoje, mas também no tempo do passado e do futuro. O reverberar, que nada mais é do que o refletir, faz com que se reproduza imagens, conteúdos simbólicos e arquetípicos, ou seja, conteúdos que transcendem e existem.

Para que toda essa ampliação do símbolo ocorra, torna-se necessário que o símbolo traga os conteúdos vitais pelos quais se vive.

O Canto é um elemento estruturante para o ser humano, quer em sua história filogenética, colaborando na construção cultural, fazendo parte do universo simbólico de todas as culturas, quer em sua história ontogenética, graças à qual, cada indivíduo, ao nascer, utiliza vocalizações para iniciar o intercâmbio com o mundo. O homem vem, então, expressando-se musicalmente através da voz: nos cantos de trabalho, nos cânticos guerreiros, nos cantos religiosos ou sacros, nos acalantos de mães ou pais embalando filhos, nas festas, nos jogos, na crônica social de época, nas óperas associando dramas e mitos ao canto, nas canções populares... Enfim, em suas atividades, talvez mais significativas, o ser humano lança mão do cantar. (Millecco, 2001, p.109)

Na época em que foram e que são feitas as canções, os artistas imprimem não apenas a sua vida, ou seja, seu trabalho, divertimento, mas também, e principalmente, todo o contexto no qual estão inseridos, como as guerras, a repressão, a seca. Isso tudo fica muito evidente quando se tem contato com canções como Asa Branca, de Luiz Gonzaga, o Hino de Duran (Hino da repressão), de Chico Buarque, e tantas outras. Elas não tratam apenas de experiências individuais do compositor, mas de todo um contexto no qual estão inseridos e isso faz com que esse símbolo seja entendido e tenha significação para muitas pessoas. Assim, elas passam a ser utilizadas como a expressão de um povo.

Outro tipo de canto de grande importância para a compreensão do aspecto da expressão de conteúdos arquetípicos são os cantos religiosos ou sacros. 
Talvez seja o canto, uma das mais antigas maneiras do homem entrar em contato com o transcendente, com as forças divinizadas da natureza, com a idéia de um ser supremo. As canções e danças indígenas, os cantos Gregorianos, os mantras, as ladainhas, os spirituals, os "pontos" de terreiro, as incelênças, enfim, as evocações religiosas, funcionam como um canal de comunicação entre céu e terra, entre homem e Deus. (Millecco, 2001, p.48)

Tanto esse tipo de canto como a canção que fala da seca, a Asa Branca, levam a uma reflexão sobre algo maior, sobre a existência. Algo que iguala os indivíduos aos demais seres e que coloca a dor não mais como única, mas como a dor de um povo, de uma civilização.

\section{Um olhar do musicoterapeuta sobre a canção}

Bruscia, em seu livro Definindo Musicoterapia, traz uma definição de trabalho, em que consta que "Musicoterapia é um processo sistemático de intervenção em que o terapeuta ajuda 0 cliente a promover a saúde utilizando experiências musicais e relações que se desenvolvem através delas como forças dinâmicas de mudanças." (Bruscia, 2000, p.22)

Dentro dessas experiências musicais, existem as classificações de técnicas e recursos utilizados na prática musicoterapêutica, tais como as técnicas da recriação, composição, audição e improvisação, bem como recursos instrumentais, áudios e canções.

É importante ressaltar que a canção pode ser utilizada dentro de todas as técnicas citadas anteriormente, mas cabe enfatizar que a canção não é o único canal de expressão na musicoterapia.

$\mathrm{O}$ ato de cantar está muito presente em nossa sociedade. E é pelo povo que a canção, a composição do autor, se torna popular, difundida, ou seja, a canção que o autor criou, passa a ser um significante para o povo. E é dessa forma que 0 símbolo emerge, uma vez que a canção contém vivências, experiências, imagens da natureza em que se vive e que se sente.

As imagens produzidas pela psique podem ser altamente pessoais, mas o drama em nos- so palco interior costuma ser uma encenação do drama humano geral. Os artistas e os sábios sempre souberam disso. Nossos problemas particulares - nascimento, morte, relacionamentos, conflitos e a busca de significado - são problemas humanos. Quem estiver passando por um deles tem chance de perceber que essa experiência é uma versão de imagens grandiosas que simbolizam o medo como a humanidade sempre vivenciou esse problema. Jung chamou de arquétipos essas imagens atemporais. São dinamismos que fornecem padrões de um comportamento, de emoção e de experiências pessoais que transcendem a história pessoal. (Whitmont, 1991, 47)

O autor Milton Nascimento, como tantos outros autores, consegue imprimir esses "dramas humanos", dos quais o autor fala acima. Dentre tantas canções da autoria de Milton Nascimento, uma em especial se encaixa dentro da abordagem desse trabalho, a canção intitulada: Certas Canções.

tro de mim

“Certas canções que ouço cabem tão denquem fiz.

que perguntar carece como não fui eu

Certa emoção me alcança corta minha alma sem dor. se 0 amor."

Certas canções me chegam como se fos-

(Certas canções - Milton Nascimento)

"Como não fui eu quem fiz"? Certas canções falam tanto da vida, que, por um instante, se confunde, como se passasse de uma canção para um relato de vida pessoal. E é essa "mágica" que a canção, como portadora de elementos simbólicos, nos proporciona.

Na estrofe “...eu perguntei a Deus do céu, por que tamanha judiação." (Asa Branca - Luiz Gonzaga), percebe-se que a judiação, a dor do povo relatado na canção, é de uma realidade, mas a dor não é só de domínio desse povo, mas de todo ser humano, daí a capacidade de ampliação do símbolo, do significado que damos a ele. Percebe-se a "Quem" se refere a súplica, a indagação, o pedido. A constelação do arquétipo do "Pai" reflete a ajuda, o amparo, o consolo, que tanto necessitam nesse momento.

É importante que a canção seja esmiuçada até que o símbolo seja ampliado e significado 
para o paciente, ou seja, que o paciente se sinta atingido, tocado pela mensagem. Isso fica muito evidente quando o paciente canta a canção uma vez, mas não compreende o que cantou e nem está predisposto a "receber" o significado do símbolo.

Através de canções, eles podem comunicar seus problemas, suas necessidades ou desejos insatisfeitos do passado ou do presente, suas alegrias, sua solidão. Eles podem ser lembrados de períodos tristes ou felizes que podem providenciar uma introspecção maior de seus problemas do presente, ou que podem levá-los para longe de seus desconfortos imediatos. Através do ouvir ou cantar canções, eles podem aprender ou ensinar, podem experimentar ou re-experimentar fatos e sentimentos, podem tocar ou ser tocados pela audição. (Bailey, 1984, p. 6)

Nesse sentido também se pode dizer que foram tocados pelo símbolo. Isso que a autora fala acima só pode ser entendido dentro do pensamento simbólico, uma vez que os problemas, as necessidades e desejos, não são somente expressos de forma verbal, mas pelas palavras das canções. Estas, contendo material simbólico, permitem fazer associações, ligações, ressignificá-las com a vida pessoal do paciente. Nem sempre essa expressão provém dos pacientes, em termos do ato de cantar. Muitas vezes, a escuta da canção contém letras, das quais emergem símbolos, mensagens de que estavam precisando.

Dentro da prática musicoterapêutica com pacientes com câncer, percebe-se que uma das primeiras necessidades dos pacientes é falar, cantar algo que os "leve" daquele lugar, daquela situação. Não é por acaso que, em alguns atendimentos, solicitam canções "alegres", contradizendo, saindo do estado em que se encontram. Quando se percebe que é a vontade e a necessidade deles de "fugirem" um pouco daquela realidade, pedese que recordem de canções da infância e épocas significativas de suas vidas, como o namoro. Não são raras as vezes em que as risadas e expressões de lembranças alegres vêm ao rosto, antes de expressarem as canções. Aqui fica muito evidente 0 aspecto do espaço atemporal que a canção proporciona. Ela permite que as lembranças, as cargas afetivas venham à tona, no momento em que são resgatadas as canções. Muitas também são as histórias que vêm atreladas a essas canções. É um momento de intenso prazer, alegria e distanciamento, nem que por alguns minutos, daquela situação real que estão vivendo e sentindo. Deve-se ressaltar que o trabalho da musicoterapia, realizado com os pacientes oncológicos, é feito durante a quimioterapia, portanto, num momento em que para uns há dor, desconforto e muita tensão.

O conteúdo de canções é significante. Pessoas preferem ouvir e participar de canções que expressem suas necessidades e que convém ao ânimo e às mensagens que eles desejam ouvir. Informações variadas a respeito das necessidades físicas, emocionais e espirituais de pacientes e famílias podem ser obtidos ao prestar mais atenção às canções que eles escolhem e às razões para suas escolhas. Os conteúdos da escolha ou lembranças. (Bailey, 1984, p.7).

Dentre as canções que aparecem com mais freqüência entre os pacientes com câncer, pode-se dizer que uma em especial acompanha 0 trabalho do início até o presente momento: "Nossa Senhora", de Roberto Carlos. O símbolo de cuidado, de ajuda, que essa canção contém, é ampliado por muitos, uma vez que a situação em que estão vivendo pede pela ajuda, pelo cuidado. A canção fala do pedido pelo cuidado:

"Nossa Senhora me dê a mão. Cuida do meu coração.

Da minha vida, do meu destino, cuida de mim."

(Nossa Senhora - Roberto Carlos)

É importante ressaltar, mais uma vez, que a ajuda é pedida a um plano maior, um plano transpessoal, o arquétipo está novamente presente.

Segundo os estudos da autora Kübler-Ross (2000), dentro de um processo do morrer, existem cinco estágios pelos quais se passa, a saber: a negação, a raiva, a negociação, a depressão e a aceitação. O caso a ser relatado agora é de uma paciente que se encontra numa fase de transição entre a depressão e a aceitação.

Quando a musicoterapeuta chega à sala, a paciente está chorando e algumas enfermeiras dizendo a ela que não tem por que chorar, que, pelo contrário, deve ficar alegre. Aqui cabe fazer uma constatação perante a dificuldade dos profissionais de saúde em darem suporte à dor emocio- 
nal dos seus pacientes. Esses profissionais não são preparados para lidar com a dor emocional, e sim, apenas com a dor física. Em alguns casos, os pacientes sentem uma angústia muito grande por não serem compreendidos na sua dor, uma vez que ela não se divide em dor física e emocional. Voltando ao relato do caso, a paciente disse que não estava encontrando lugar para chorar em sua casa, que apenas o conseguia fazer, à noite, em seu quarto. A musicoterapeuta então cochichou com ela, que fariam daquele lugar e daquele momento, um local para chorar, porque o choro faz bem. Antes mesmo de terminar de falar, o choro ganhou espaço e saiu. Enquanto isso, a musicoterapeuta pediu licença para tocar e cantar uma canção, "Aquarela", de Toquinho e Vinícius de Morais. Foi escolhida "Aquarela", por falar de um futuro do qual não se tem controle, por falar de um fim que chega para todos:

"Basta imaginar ele está partindo sereno e lindo e se a gente quiser ele vai pousar."

E o futuro é uma astronave que tentamos pilotar; não tem tempo, nem piedade, nem tem hora de chegar.

Sem pedir licença muda a nossa vida e depois convida a rir ou chorar.

Nessa estrada não nos cabe conhecer ou ver o que virá.

O fim dela, ninguém sabe bem ao certo onde vai dar.

Vamos todos numa linda passarela de uma aquarela, que um dia enfim, descolorirá."

(Aquarela - Toquinho/Vinícius)

A musicoterapeuta pediu que, dentro do possível, a paciente a acompanhasse no canto, uma vez que apresentava dificuldades de respiração devido a um câncer no pulmão. Cantaram, conversaram, a paciente chorou e, em um determinado momento, perguntou o que a musicoterapeuta tinha para dizer a ela. Esta olhou em seus olhos e perguntou o que a paciente gostaria de dizer a ela mesma. O choro veio com mais força, juntamente com a frase: "Que eu não tenho cura". A constatação e aceitação tinham ganhado espaço para a expressão, uma vez que em sua casa não havia espaço para esse diálogo. A musicoterapeuta acolheu a sua constatação e ficou num movimento mais de escuta, uma vez que era isso que não estava encontrando, mas precisando. Mas, também, teve um movimento de confirmá-la dentro da sua dor e de uma morte iminente. Como já sabia de seu estado terminal, a canção "Aquarela" não foi escolhida por acaso. A musicoterapeuta trouxe essa canção por revelar que ela não tinha mais cura e que a morte é algo que vem para todos, que faz parte da vida. Ao final, quando foi solicitada uma canção para o próximo encontro, a paciente pediu a canção: "Se eu quiser falar com Deus", da autoria de Gilberto Gil. Naquele instante, a musicoterapeuta pôde compreender que o coração da paciente estava mais aliviado e que o medo da morte tinha sido amenizado, e talvez até superado.

"Se eu quiser falar com Deus

Tenho que ficar a sós

Tenho que apagar a luz

Tenho que calar a voz

Tenho que encontrar a paz

$\cdots$

Se eu quiser falar com Deus

Tenho que me aventurar

Tenho que subir aos céus

Sem cordas pra segurar

Tenho que dizer adeus

Dar as costas, caminhar

Decidido, pela estrada."

to Gil)

(Se eu quiser falar com Deus - Gilber-

É dessa forma que a canção pode falar a respeito dos pacientes, pode ajudar a compreendê-los e, principalmente, eles compreenderem a si próprios, dentro da situação em que estão vivendo. Nos momentos em que palavras não podem ser ditas ou nem se consegue mais dizê-las, as canções ampliam e "falam" a respeito de seus sentimentos e vivências para eles mesmos. "Mensagens contidas nas canções podem providenciar suporte para necessidades internas e podem ajudar pessoas a processarem perdas e aflições. Canções podem evocar imagens prazerosas e podem provocar alegria." (Bailey, 1984, p.12)

Compreende-se que a canção, como portadora de conteúdos simbólicos, torna-se um veículo de comunicação entre o consciente e o inconsciente. Dessa maneira, tem-se a possibilidade de uma melhor adaptação e compreensão de conteúdos do inconsciente.

É importante ressaltar que o símbolo não traduz, elucida ou decifra, mas sim, amplia e 
ressignifica. Dessa maneira fica claro que o musicoterapeuta não pode classificar as canções, dizendo que aquela fala disso e assim por diante, porque não se trata de um sinal, mas de um símbolo e, como tal, só pode ressignificar a partir das vivências de cada indivíduo.

Como foi relatado no trabalho, constatouse que a canção, devido ao seu caráter simbólico, nem sempre diz algo de que gostamos ou queremos, mas sim, do qual se está precisando, algo por muitas vezes inesperado.

Além disso, a canção permite aos musicoterapeutas a compreensão dos seus pacientes, bem como do momento que estão vivendo, em que as palavras cantadas soam melhor e mais fáceis aos ouvidos, ao entendimento e ao coração, possibilitando uma comunicação mais eficaz e autêntica.

\section{Referências}

Bailey, L. M.(1984). The Use of Songs in Music Therapy With Cancer Patients and Their_Families. The Journal of the American for Music Therapy: New Jersey - EUA, 4(1).

Bruscia, K. E. (2000). Definindo a Musicoterapia. Rio de Janeiro: Enelivros.

Bruscia, K. E. Complexo. (1997). In Ferreira, A. B. de H. Dicionário Aurélio. Rio de Janeiro: Nova Fronteira.

Conde, C. Orelha do livro. (2001). In Millecco Filho, Luis Antônio. É preciso cantar: Musicoterapia, cantos e canções. Rio de Janeiro: Enelivros.
Costa, M. S. R.(2001). Prefácio. In Millecco Filho, Luis Antônio. É preciso cantar: Musicoterapia, cantos e canções. Rio de Janeiro: Enelivros.

Kast, V. (1997) A dinâmica dos símbolos: fundamentos da psicoterapia junguiana. São Paulo: Loyola.

Kübler-Ross, E. (2000). Sobre a morte e o morrer. São Paulo: Martins Fontes.

Langer, S. K. (1953). Sentimento e forma. São Paulo: Perspectiva.

Langer, S. K. (1989). Filosofia em nova chave. São Paulo: Perspectiva.

Langer, S. K. (1991). Retorno da Deusa. São Paulo: Summus.

Millecco Filho, L. A. (2001). É preciso cantar Musicoterapia, cantos e canções. Rio de Janeiro: Enelivros.

Samuels, A.(1989). Jung e os pós-junguianos. Rio de Janeiro: Imago.

Seabra, Z. (1996). Tempo de Camélia - o espaço do mito. Rio de Janeiro: Record.

Ulson, G. (1988). O Método Junguiano. São Paulo: Ática.

Whitmont, E. C. (1969). A busca do símbolo: Conceitos básicos de Psicologia Analítica. São Paulo: Cultrix. 